\title{
Selected aspects of the impact of the digital world on the training of personnel for the mining industry in the region
}

\author{
Tatiana Panina*, and Sergey Dochkin \\ T.F. Gorbachev Kuzbass State Technical University, Mining Institute, 650000 Kemerovo, the Russian \\ Federation
}

\begin{abstract}
The article considers the aspects of organizing targeted training of personnel for mining enterprises in the region in the context of its innovative development. Based on the analysis of various approaches to the diversification of the region's economy, two main ones are identified: process and cluster, a reasonable combination of which can provide the required potential for innovative development of the coal industry and related sectors of the region's economy. Special emphasis is placed on the training of personnel, without which it is impossible to introduce innovations in all key areas and at the main stages of the activities of coal companies. At the same time, globalization and the emergence of a new digital world and information society have created new perspectives in understanding the essence of adult education, which in the digital economy has its own characteristics, and new approaches are required to solve the problems of training personnel in a high-quality way. In these conditions, the education system appears as a network of active participants with a variety of educational practices, the presence of which is determined by personal and professional needs. It is necessary to ensure the transition from general, technological and algorithmic adult educational practices to unique and individual ones. The point of such a transition is not to discover new ones, but to select individual combinations of existing practices, strategies, and technologies. Individualized selection of sets of practices and educational strategies is becoming the dominant trend in adult education in the modern era. Practical implementation of the considered aspects will allow us to build the educational process in a different way and mutually beneficial interaction of organizations of additional professional education with consumers of educational services, which will ensure the practical implementation of models of harmonization and "economic rebranding" of the resource-intensive region, the creation of an institutional infrastructure for its harmonious development.
\end{abstract}

\footnotetext{
* Corresponding author: pts.idpo@kuzstu.ru
} 


\section{Introduction}

The issues of the need to transfer the Russian economy from a resource-based to an innovative model of functioning are currently becoming particularly relevant. At the same time, the importance of innovative development of raw materials regions, which include Kuzbass, is so high that it is considered a matter of survival of the region and the industry. Within the framework of the research conducted by the specialists of the Institute of Economics and Industrial Production Organization SB RAS, two dominant groups of opinions were identified on determining approaches to the development of the innovative component in the raw materials industries, in particular in the Russian coal industry: the process approach and the cluster approach. The process approach involves the introduction of various types of innovations in all key areas and at the main stages of the coal company (and the industry) in order to increase its value and create strategic competitive advantages. The cluster approach, as a basic element of the system of innovative development of the coal industry, considers the coal industry cluster - an interconnected chain of complementary and mutually reinforcing multi-industry innovative industries for the extraction, processing and efficient use of products [1].

However, the implementation of these approaches is impossible without the availability of highly qualified personnel and their high-quality training and retraining in accordance with the implemented technologies and innovative models. Considering the process approach, the specialists of the SB RAS noted that one of the main industry risks for the domestic coal industry is the shortage of highly qualified personnel and low labor productivity in our country compared to the main global competitors. These factors, together with others, cause a decline in the competitiveness of the Russian coal industry in the global and domestic markets. Accordingly, among the ways to solve this problem, we distinguish, first of all, an increase in labor productivity, the efficiency of production and use of coal products, which, in fact, cannot be implemented without highly qualified personnel. The implementation of the cluster approach is also impossible without staffing. Only with the availability of personnel, it is possible to form and develop a system of regional and municipal institutions to support innovations in the basic coal industry and other sectors of the economy, to form multi-industry complexes, the starting point for which is coal, which actually ensures the creation of promising points of economic growth in this territory [1]. The complementary nature of the process and cluster approaches in the planning of innovations in the coal industry should be noted. If the process approach takes into account various aspects of the innovative movement of the coal business, the cluster approach allows us to fully understand the multiplying potential of the impact of the innovative development of the coal industry on related industries and the economy of the coal mining region.

Thus, in modern conditions, not just traditional professional education, which is rather inert and non-operational, is becoming increasingly important, but adult education within the framework of the system of continuing education. It is believed that it provides a person with the opportunity to adapt to changing conditions, to compensate for the lack of previously acquired knowledge, to realize their needs and interests, to help overcome feelings of uncertainty and uncertainty, to feel protected from many problems of modern life. It is adult education that can become the basis for the implementation of innovative development of the region within the framework of the integration of process and cluster approaches [2].

At the same time, the basic organizational approaches to adult education are no longer new, and it has been implemented quite actively for more than ten years, however, it has not been possible to achieve systematic results across the country, despite a number of national projects, such as "Demography", and federal projects ("Older Generation", 
"Employment Promotion", etc.) aimed at training/ retraining the adult population, including promising areas and professions, professions that require innovative production.

The system of additional professional education tries to respond actively and promptly both to the tasks set and to changes in the conditions in which organizations that implement additional professional programs have to function. One of the main problems is the low activity of interested persons, primarily those categories of the adult population that these programs and projects are aimed at. Moreover, even the implementation of additional professional programs, which are attended by young people and middle-aged people, face paradoxical phenomena. As our research has shown, more than half (54-57 \%) of trainees enroll in advanced training programs (professional retraining) not because they need it, but because they are sent by employers in accordance with regulatory requirements; $65 \%$ of students indicate that the development of a particular additional professional program will not lead to their career growth or improvement of their financial situation; up to $27 \%$ of students believe that they could do without the competencies and skills offered for development; at the same time, $85 \%$ of students of professional retraining programs begin their studies only because they are unable to engage in professional activities without confirming their education documents [3].

This attitude leads to the fact that even after the beginning of training, students of advanced training courses or professional retraining show passivity in the classroom, little interest, not a high level of attendance, do not strive for high results, and do not take the final certification seriously. It should be noted that the existing system of providing educational services and paying for them contributes to this attitude, since often the expulsion of a student due to poor performance, due to non-fulfillment of the curriculum or absence from classes is not expected or leads to the return of tuition fees, regardless of the costs incurred by the educational institution [4].Competition in the market of educational services also plays a role, when the number of offers of various courses from organizations of additional professional education exceeds the demand for them. This leads to the fact that a potential client (an adult applicant) chooses courses that can be mastered faster, without large financial and intellectual costs and get the appropriate document, relatively, not high-quality programs that involve a responsible approach to its development, but more "easy", simplified and cheap become more competitive.

It is interesting to note that in this situation, the entire responsibility for professional development/professional retraining of a specialist (listener), for its effectiveness, falls primarily on educational organizations of additional professional education [5].For this reason, andragogy is being developed, innovative pedagogical technologies, active and interactive teaching methods are being developed and tested by teaching teams, educational environments and educational electronic spaces, distance and e-learning systems are being formed, mass open online courses, competence centers, advanced training centers, business centers, etc. are being created.

The development and active introduction into practice of additional professional education, and adult education in particular, modern information technologies, network services and digital tools also has did not caused a sharp demand for additional educational services, and has not led to an increase in the demand for distance courses and mass open online courses. In practice, the benefits of distance education, which have been talked about for almost twenty years, have turned out to be a myth. The opportunity to learn "at your own pace", not according to the "schedule", not in the classroom "from a bell to a bell", but "at a convenient time, in a convenient place, at a convenient pace" led to the fact that adult listeners (by definition more conscious than primary school students) almost stopped studying the material in the off-line mode [6]. The situation with online training also does not inspire optimism - if earlier the leading developers of training platforms tried to present users with the most convenient and comfortable environment with a friendly interface, now 
these environments are being increased by means of attendance control and maintaining the forced activity of listeners during virtual events.

A comparison of the attendance of professional retraining courses over the past three years revealed the following trend: being late and omission of full-time classes in the classroom was performed by an average of $15-18 \%$ of students for the entire period of training, at the same time over the past year, during which most classes were held remotely, this figure increased almost twice - to $27-33 \%$. And this is despite the fact that arriving in the classroom at the beginning of the lesson is often more difficult than "entering" a virtual room using a handy gadget (personal computer, laptop and smart phone). It seems surprising, but up to $68-73 \%$ of students in each of the groups at the end of the last year of training were in favor of transferring classes from a virtual environment to a traditional environment, "class-time", which at one time was proposed to abandon innovators and reformers [4]. The facts marked above make you think that- may be not only the specific organization of the educational process in institutions of additional professional education, the educational practices used by them and the training of teaching staff, but also the adult student himself?

The digital world and the modern information society fundamentally raises a new question about the nature of a man and his training. Since the end of the XIX century, the meaning of the concept of "education" has shifted towards the process of mastering knowledge, information, and certain practical skills, which eventually led to the emergence of the phenomenon of professional education, when socialization involves obligatory professionalization. The philosophical basis of the traditional system of professional education is the model of an adult in classical philosophy, where education has become understood as a "universal cultural need" (according to M. Scheler) [7]. In fact, the educational process in the adult education system began to be built within the framework of the communicative paradigm as "understanding education", as bringing meaning into reality, as the acquisition of educational experience (or the cumulative experience of people, or the personal experience of an individual) [8].

It is interesting that the philosopher M.Foucault regarded education as not a social institution, but as an attitude, as "a way of relating to relevance" [9]. Foucault's understanding of education is "a voluntary choice made by individuals, ... a way of thinking and feeling, a way of acting and behaving that simultaneously ... acts as a task" [10]. Education does not liberate a person in his own being; it forces him to "engage in the processing of himself". Consequently, the education of an adult in the modern world, as M. Foucault writes, "does not seek formal structures of universal significance, does not seek to identify universal structures of possible cognition or moral action". Adult education is a constant study of the events that led him to self-awareness of himself as a subject of action, thought and utterance" [9].

Globalization and the emergence of a new digital world and information society have created new perspectives in understanding the essence of adult education. At the end of the $\mathrm{XX}$ century, education began to be recognized as a system-forming factor of the economy and society as a whole, but only an adult is a real subject of economic, social and cultural transformations, only an adult can be a real subject of economy and law. Consequently, it is not education in general that is being globalized, but adult education. At the same time, it should be remembered that each historical epoch is based on different types of work, and in each of them the relationship between adult education and work is different [11]. For example, the educational practices of adults in an agrarian society are educational practices of imitation, in an industrial society they are practices based on machine labor and highly specialized professional education; in the information field-based on information, methods of its processing and the ability to use it [8]. In relation to our period and a particular region, innovative practices are most in demand, for example, initiatives to diversify the 
economy by creating new, non-core industries for the region that are not directly or indirectly related to coal mining and processing (tourism, oil refining, automotive industry, deep processing of wood). According to the researchers of the SB RAS, it is for these reasons that there are no sufficient competitive advantages in the region, and for a number of objective reasons, one of which is the lack of sufficient human resources [1].

The digital world, information technologies and network services are changing the place and role of adult education in the analysis of system-forming factors of economic development, because the ontology of the adult, his time and space, his way of life is changing. The opening of access to information is possible precisely as free access to education. Information networks connect people who have approximately the same level of education, one way of seeing the world, due to this, there is a "sense of inclusion" in the digital world and the world information space, a sense of belonging to the world community.

This is the basis for the conclusion that the changing digital economy redefines and rethinks the problem of lifelong adult education, which is beginning to be considered as a "lifelong education", as a civilizational phenomenon.

The globalization of information and adult education creates not only new opportunities, but also new challenges, such as how to ensure that millions of adults can master the practice of effective use of new social and information technologies. According to A. Vefleemskiy, the use and dissemination of information and knowledge in the information epoch largely depends not on technology, but on social institutions, primarily on the educational complex [12].

Modern society has an information resource - a set of information and means of processing it, in which information distribution systems and systems for converting it into knowledge are important. But the existing information resources are not sufficient for the transformation of information into knowledge, this requires a specially organized educational process, which is concluded in the educational complex (according to A. Vefleemskiy) [12]. The economic nature of the educational complex is determined by the specifics of knowledge as a resource that has an unlimited volume, and when consumed, the amount of knowledge does not decrease, but increases. Accordingly, an educational institution has the ability to repeatedly sell its educational services and its economy is limited by demand, but not by the volume of knowledge sold. At the same time, the educational complex is characterized by the peculiarities of pedagogical work, in which the most popular is the use of interactive teaching methods. This requires the teacher to have up-to-date knowledge, talent and skills in organizing classes based on an integrated interactive model, the ability to use visual means of the Internet and network services. In turn, the network theory opens up prospects for the development of the adult education system, but it also increases the responsibility of the adult learner for responding to interactive actions during the learning virtual interaction.

It is information that currently plays a decisive role in understanding the status of education of the modern adult. We are talking about the phenomena of "open universities", distance education, e-learning, and "education for all". In the space of the network, its active participants are located, who, interacting in virtual space (in semantic space) at a distance of thousands of kilometers from each other, are actually located closer than their neighbors in the house [13]. Moreover, we are now seeing a tangible diversity of coexisting networks, where one participant operates in several of them at once, following different rules. A person finds himself immersed in the multidimensional space of networks, while he builds a multidimensional space by his own actions and uses multidimensional educational practices.

In this regard, in the digital world and the information society, the education system appears as a network of active participants with a variety of educational practices, the 
presence of which is determined by personal and professional needs. And here it is important to understand that the totality of educational practices for each adult is individual, just as each educational practice is individual. This means that adults form and use unique, singular educational practices. Other people can not adopt them, because they have a different spatial and temporal incarnation, different tasks and life priorities. The complexity of adult education is related to the ways of acquiring educational experience - educational practices of an adult, in fact, the "life world" of a modern adult is a web (developing network) of educational practices [8]. And any way, method, or way of transforming one's own essence that modern adults build up is determined by different educational practices.

The process of transition from general, technological and algorithmic educational practices of adults to unique and individual ones can be represented as the realization of the contradiction of the "single - universal". The modern adult is an "experimenter" in the use of social practices and their aggregates [8]. The point of experimentation is not to discover new ones, but to select individual combinations of existing practices, strategies, and technologies. Individualized selection of sets of practices and educational strategies is becoming the dominant trend in adult education in the modern era.

At the same time, it should be understood that despite the fact that the development of adult education co-exists with the explosive growth and development of information technology (IT), the new meanings of education are not technological. These meanings are predominantly cultural and independent of economic and technological changes. Their humanistic spirit largely influences the desire for individualized, decentralized use of technology and participation in the economy. It can be concluded that information technologies and network services implement various forms of individualized social existence of an individual, but in this case the adult individual must first of all be active to achieve a certain goal, in the case of education it is an educational one.

In fact, at present, adult education should not be considered as a service that brings "comfort and pleasure", but as a criteria that divides people into an active, self-organized elite that is able and willing to construct their own values based on experience and educational practices, and marginals who are deprived of information, resources and power, and do not want to acquire them. Awareness of the considered aspects, in our opinion, should allow developing the educational process and equal and mutually beneficial interaction of organizations of additional professional education with consumers of educational services in a different way. As a result, the effects of these processes will ensure the practical implementation of the models of harmonization and "economic rebranding" of the region, the creation of an institutional infrastructure for the harmonious development of the region of the resource type of a new formation based on the principles of reindustrialization and digitalization.

\section{References}

1. V. A. Kryukov, Yu. A. Fridman, G. N. Rechko, E. Yu. Loginova, Kuzbass in the New Time-Novosibirsk: Publishing House of IEOPP SB RAS, 180 (2020)

2. A. Khoreshok, A. Kuznetsov, A. Shalkov, E3S Web of Conferences, 41, 03004 (2018)

3. T. Panina, S. Dochkin, E3S Web of Conferences, 105, 04039 (2019)

4. T. Panina, N. Kostyuk, S. Dochkin, E. Pahomova, Dilemas contemporaneous: Education, Politics and Values, 6(8), 4 (2019)

5. V. Bobrikov, N. Ravichkin, V. Shshenniko, E3S Web of Conferences, 41, 04014 (2018)

6. L. R. Goldberg et al., Journal of Research in personality, 40(1), 84 (2006) 
7. M. Scheler, Sociology of knowledge, Theoretical sociology: An Anthology In 2 parts. 1, 160 (2002)

8. N. Yu. Ignatova. - Nizhniy Tagil: NTI UGTU-UPI, 118 (2005)

9. M. Foucault, Bulletin of the Moscow University. Ser. 9. Philology, 2, 132 (1999)

10. G. A. Gachev, National images of the world. Cosmo-Psycho-Logos (Moscow, Progress, 2001)

11. R. Patterson, The T-Shaped Person: Building Deep Expertise AND a Wide Knowledge Base, https://collegeinfogeek.com/become-t-shaped-person/

12. A. D. Vifleevskiy, The role of the educational complex in postindustrial society, $\mathbf{8}, 16$ (2002)

13. M. Castels, The information age: economy, society and culture (Moscow, Higher School of Economics, 2000) 